\title{
Document examination in criminalistics and forensic sciences: New approaches and modern technologies
}

\author{
VALERY SHEPITKO \\ ORCID: 0000-0002-0719-2151 \\ Criminalistics Department, Yaroslav Mudryi National Law University \\ Kharkiv, Ukraine \\ MYKHAYLO SHEPITKO \\ ORCID: 0000-0002-7164-8037 \\ Criminal Law Department, Yaroslav Mudryi National Law University \\ Kharkiv, Ukraine
}

\begin{abstract}
Document examination in criminalistics and forensic sciences is an activity required during the investigation and/or judicial proceedings. Using the full potential of investigative actions in document examination is an important source of evidence, which makes it possible to put the crime investigation on the right path. It is extremely important to resolve issues related with the expert examination of documents. Since the technical study of documents is the most common type of forensic studies, the article notes its transformation both towards expanding and restricting its volume. Moreover, the authors give indication of the new paradigm emerging in the examination of documents and their new forms, which highlights the need for developing new approaches and using different techniques and legal frameworks. Another important aspect is the protection of the judicial proceedings from false and erroneous forensic expert reports. To this end, forensic experts are warned of possible criminal liability and are sworn in. It is worth noting that these mechanisms are not always effective and the use of additional legal and managerial
\end{abstract}


decisions in this regard is required. Forensic experts' false and erroneous reports may be the subject of investigative actions and expert investigations.

Keywords: document examination, questioned document examination, forensic report, forensic scientist, expert witness

In the current context, the formation of forensic knowledge depends on the scientific and technological progress of humanity. The development of criminalistics and its trends are due to the impact of global information flow, the integration of knowledge about the capabilities of combating crime by way of scientific and technological achievements of the modern world. Informatization of the social environment has actually led to the "technologization" of criminalistics, the development and implementation of digital information, telecommunication, and other technologies. Modern technology is a permanent component used in the theory and practice of criminalistics and forensic sciences.

Forensic science is a form of using specialized knowledge (including criminalistic knowledge). It is considered to be professional knowledge and skills in the field of science, technology, art, craft, etc., necessary to resolve issues arising during the pre-trial investigation and evidence consideration in court. ${ }^{1}$ In literary sources, specialized knowledge is defined as knowledge based on certain science having a theoretical basis, necessary for understanding the nature of phenomena, their properties, both obvious and hidden; in addition, this knowledge must be acquired during special training, the holder of this knowledge must not only be specially trained theoretically, but also possess practical skills in applying his knowledge in the given specialty. ${ }^{2}$

Specialized knowledge embodies the linkage between results achieved through research and practices requiring some preparation; it cannot be ordinary, widespread knowledge obtained in the general education process. ${ }^{3}$ It is not a common set of information, but a dynamic entity that is constantly evolving, qualitatively and quantitatively increasing, since,

1 Kochura O.O., "Definition of the concept of 'specialized knowledge' and its use in criminal proceedings", [in:] Current trends in the development of criminalistics and criminal trial, Kharkiv, 2017, p. 285.

2 A.A. Korabliov, "Forms of using specialized knowledge in criminal proceedings", Society: Politics, Economics and Law 2016, no. 2, pp. 132-135.

3 N.M. Kosmina, "Specialized knowledge of informed persons during the investigation of drug trafficking and its structure", Forensic Bulletin 19, 2013, no. 1, p. 25.

Nowa Kodyfikacja Prawa Karnego 59, 2021

(C) for this edition by CNS 
as is known, experience has the tendency to accumulate. ${ }^{4}$ Specialized knowledge should contribute to the reliable establishment of evidence, not merely its study, and the person conducting the research (expert) should use proven methodologies, equipment, and materials to secure high accuracy of the results. ${ }^{5}$

In criminalistics and forensic sciences, document examination is given earnest consideration. In the field of "criminalistic technique", some of its branches, such as "questioned and criminalistic document examination," are traditionally regarded.

Questioned document examination is the most common type of criminalistic examination. Its principal focus are facts and circumstances related to the production of documents, the technique of introducing changes, identifying invisible records established on the basis of specialized knowledge in technical research (criminalistic technique research) of documents in the manner prescribed by law. ${ }^{6}$ In accordance with the instructions on the designation and conduct of forensic examinations and expert studies (approved by order of the Ministry of Justice of Ukraine on 8.10.1998 No. 53/5), questioned document examination is divided into the examination of document details, printed forms, and document materials.

In the current context, attempts have been made to change the criminalistic document examination as a branch of criminalistic technique, replacing it with "criminalistic documentation" or "criminalistic records management." In particular, it is proposed to consider criminalistic documentation (document studies, document science, documentoscopy) as a system of scientific knowledge about the types of documents operating in criminal proceedings as well as the means, techniques, methods of their investigation, the use of this information for legal and criminalistic purposes. ${ }^{7}$

4 I.I. Kohutych, "Selected issues of the essence and forms of using specialized knowledge in criminal proceedings", Bulletin of the Academy of Advocacy of Ukraine 12, 2015, no. 2, p. 113.

5 M.A. Maliutin, "Specialized knowledge as examination evidence", OSU Bulletin 139, 2012, no. 3, p. 96.

6 O.V. Vorobey, "Forensic-technical examination of documents: Basic concepts, origin and prospects of development", Judicial Practice 2010, no. 11-12, p. 20.

7 For more details see: M.V. Saltevskyi, Criminalistics, vol. 1, Kharkiv 1999, p. 416.

Nowa Kodyfikacja Prawa Karnego 59, 2021

(C) for this edition by CNS 
These proposals are not random, since the scope of the criminalistic technique document examination is expanding, the essence of the document itself as well as the objects and methodology of expert research are changing.

The transfer of information through documents is an important milestone in mankind's development. The documents themselves have also changed significantly: from rock art and images of ancient people to the use of papyrus, and from written documents to electronic ones.

In criminalistics, a document is defined as a material object which contains information about any past or alleged facts, ${ }^{8}$ recorded using an artificial language or in the form of graphic images, by a person or using scientific and technological inputs intended for its transmission in space and time. ${ }^{9}$ In accordance with the Ukrainian Law on Information, a document is a tangible medium containing information, the main functions of which are its storage and transmission in time and space.

In Ukraine, three document definitions are officially adopted:

1. SSTU ${ }^{10} 2392-94$. Document I. Recorded information which is considered to be a unit in the process of carrying out information activities;

2. SSTU 3017-95. Document II. A material object with information formalized by a human-made method for its transmission in time and space;

3. SSTU 2732-94. Document III. A material object that contains formalized information, drawn up in accordance with the established procedure and having legal significance in accordance with the legislation in power.

The document should include certain details, namely mandatory requirements for its execution. The State Standard of Ukraine (SSTU 4163: 20) establishes the requirements for document execution. In this case, when preparing documents it is necessary to use the following details: 1. a design of the State Coat of Arms of Ukraine; 2. a trademark image (a mark for goods and services) or emblem of the legal entity; 3 . the name of the highest-level legal entity; 4. the name of the legal entity; 5 . the name of the legal entity's structural unit; 6 . the legal entity's reference data; 7 . the code of the document form; 8 . the code of the legal

8 V.Yu.Shepitko, Criminalistics: A course of lectures, Kharkiv 2005, p. 92.

9 Criminalistics: Textbook, vol. 1, ed. V.Yu. Shepitko, Kharkiv 2019, p. 149.

10 State Standard of Ukraine. 
entity; 9. the document type name; 10 . the document date; 11 . the document registration index; 12 . the reference to the registration index and the date of the document to be addressed; 13 . the place of document preparation; 14. a classification mark; 15. resolution; 16. crypto; 17. indorsement; 18. a control mark; 19. a title to the text of the document; 20 . the text of the document; 21 . a notice about the available annexes; 22. a signature; 23 . a seal impression, etc.

Currently, various approaches for ensuring the security of documents against counterfeiting are offered. Special means of protecting documents include: 1 . special security elements (e.g. holographic elements, protective tape or fibers); 2. special materials used for the manufacture of a certain document category (e.g. special paper, dye); 3. special technologies used for manufacturing documents that exclude their falsification (e.g. special design techniques, manufacture, and document decoration). ${ }^{11}$

Most developed countries have made the transition to a "new generation of documents" on a polymer basis back in the 1990s. In Ukraine, the manufacture of new generation documents is associated with the functioning of the Znak enterprise production complex, specializing in plastic cards. ${ }^{12}$ Holographic security elements are used to manufacture various identification documents with special protection means against counterfeiting: pages for foreign passports; national driver's licenses; vehicle registration certificates; crew member certificates, etc. To manufacture these documents, the enterprise uses the following types of plastic: teslin and polycarbonate. ${ }^{13}$

The instruction on designation and conduct of forensic examinations and expert studies proposed an independent type of forensic examination, namely the examination of holograms. Its objects are holographic security elements, holograms used as a means of control, image, graphic holograms, intermediate products of holographic production, such as soft-

11 O. Kobylianskyi, G. Trofimchuk, "Criminalistic analysis of special means of document protection against forgery", Entrepreneurship, Economy and Law 2017, no. 3 , p. 282.

12 V.I. Tikhonova, T.O. Zakharova, "Research of extremely advanced documents", [in:] Theory and practice of judicial examinations and criminalistics, Kharkiv 2010, p. 292.

13 Ibid., p. 292. 
ware, photo masks, and layouts, primary holograms, relief-phase original holograms, master hologram matrices, metal matrices for replicating holograms.

An independent branch of criminalistic technique related to document examination is the criminalistic examination of writing (in the narrow sense, forensic handwriting examination), a branch of science dealing with the laws of writing, the process of its study, the possibility of identifying a person by handwriting, and addressing other challenges of handwriting examination. ${ }^{14}$ When examining a letter, the whole complex of handwritten text's characteristics is analyzed, that is, both semantic and graphic aspects, although they are used for various tasks: the author of the document is identified through the written language, and its executor through handwriting. ${ }^{15}$

Analyzing expert practice shows that there is a tendency to increase the number of examinations on the study of signatures and manuscripts created on behalf of persons of advanced and senile age. The accuracy of the criminalistic methodology used for determining the writer's gender can reach no more than $80 \% .^{16}$

A new trend in the development of criminalistic technique is forensic authorship identification, which provides scientific ways of establishing the author of a text using linguistics data (phraseology, grammar, etc.). Authorship examination is a type of criminalistic examination. ${ }^{17}$

The instruction on the designation and conduct of forensic examinations and expert studies recommended running a linguistic speech examination, which is divided into a linguistic examination of written language and a linguistic examination of oral speech. In turn, the framework of the written language linguistic examination includes authorship and semantic-textual studies.

14 V.Yu. Shepitko, op. cit., p. 103.

15 I.N. Tetiuhin, K.H. Enhovatova, "Scientific basis criminalistic handwriting research”, Questions of Modern Science and Practice 56, 2015, no. 2, p. 122.

16 S.Y. Honhalo, O.H. Haiduk, L.S. Volchuk, "Unidentifying studies of handwriting: current situation and development prospects", Journal of National University “Ostroh Academy”. "Law” Series, 11, 2015. no. 1, p. 5.

17 Great Ukrainian juridical encyclopedia, vol. 20. Criminalistics, forensic sciences, juridical psychology, ed. V.Yu. Shepitko, Kharkiv 2018, p. 222. 
In modern sources, attention is drawn to the need and prospects of conducting a graphological analysis for criminalistic purposes, as well as to the relevance of reassessing the attitude towards non-traditional methods of researching the handwritten speech - e.g. graphology and the psychological analysis of writing. In this case, through writing it is possible not only to diagnose (or even identify) the author or the executor of the written document, but also to perform a more complete and comprehensive analysis of the author's personality, highlight their character, abilities, mental disabilities, and even diseases. ${ }^{18}$ Other researchers emphasize that the prospect of scientific research in graphology lies in creating an integrated approach to the study of personality through techniques that contribute to the possibility of changing the existing standards in the use of modern psychodiagnostic methods. ${ }^{19}$

The subject of document study, as a rule, is a competent person, namely a specialist or an expert. In some cases, the legislator allows other subjects to study documents within the framework of investigative (search) or judicial actions of other subjects (for example, investigator, judge, parties to criminal proceedings, etc.). In this case, it is not about conducting a forensic examination, but about studying the documents, inspecting them, or making them public.

Procedural legislation regulates investigative (search) actions such as inspection of documents, which is carried out in order to identify and record information regarding the circumstances of a criminal offense, and consists in studying and document examination to identify and capture the signs that attach to documents the meaning of physical evidence. The conduct of such an inspection is regulated by art. 237 of the Code of Criminal Procedure of Ukraine.

The term "document examination" in relation to the name of the judicial action is used in the criminal procedural law. In particular, art. 358

18 I.I. Kohutych, "Graphological analysis in criminalistics and its prospects", [in:] Interdepartmental scientific-practical collection "Criminalistics and Forensics", ed. O.H. Ruvin et al., Kyiv 2017, p. 187.

19 V.I. Kaiko, S.M. Matsyievska, "To the question of expert characterization of individual psychological features of the personality from the handwriting", Bulletin of Alfred Nobel University. Series "Pedagogy and Psychology". Pedagogical Sciences 16, 2018, no. 2, p. 58. 
of the Code of Criminal Procedure of Ukraine regulates the conduct of the abovementioned judicial action. In part 1 of art. 358 it is indicated that the protocols of investigative (search) actions and other documents attached to the materials of the criminal proceedings - if they contain or certify information that is relevant for establishing the facts and circumstances of criminal proceedings - should be announced in court at the initiative of the court or on petitions of participants in judicial proceedings, submitted for review to participants in judicial proceedings, and, if necessary, also to other participants in criminal proceedings.

A survey on judges carried out by individual investigators revealed that they had to examine the following documents during the legal proceedings: written documents (98\% indicated); graphic documents $(43 \%)$; printing documents (16\%); photo documents (85\%); phonographic documents $(45 \%)$; documentary films or visual documentation $(71 \%)$; electronic documents $(42 \%)$; other $(2 \%) .^{20}$

The investigation of the crime and the subsequent criminal proceedings requires the involvement of a forensic expert with the necessary expertise to conduct a forensic examination and provide answers to questions of interest to the investigation and/or the court. In Ukraine a guarantee of providing truthful answers to posed questions is a forensic expert's warning of criminal liability for a knowingly false expert report and a refusal to provide an expert report (art. 384 and 385 of the Criminal Code of Ukraine). It is an interesting fact that unlike other unprofessional participants in the proceedings (witness, victim), the forensic expert warns of the possibility of such criminal liability themselves (but not the judge, investigator or prosecutor), since the expert makes a corresponding note in the expert opinion (art. 102 of the Code of Criminal Procedure of Ukraine).

In accordance with art. 356 of the Code of Criminal Procedure of Ukraine, at the request from a party to criminal proceedings, a victim or on its own initiative, the court has the right to summon and question a forensic expert for the purpose of clarifying their report. Before the interrogation of a forensic expert takes place, the presiding judge will

20 I.I. Shepitko, Judicial examination in the system of judicial proceedings at first instance: A monograph, Kharkiv 2018, p. 121. 
establish their identity and they shall take the oath of the following content: "I (full name), swear in good faith to fulfill the duties of an expert, using all my professional capabilities." After being sworn in, the presiding judge (de facto once again) warns the forensic expert of criminal liability for providing a knowingly false expert opinion. Thus, the court considers these clarifications during the forensic expert's interrogation as part of the expert opinion, but not their testimony.

On the basis of the given study, as a part of this scientific paper the attempt to find a single forensic expert's knowingly false report for which they would be prosecuted (2009-2019) failed. At the same time, forensic experts are periodically subject to disciplinary actions for conducting forensic research that contains errors (but is not false). Evidence of the falsity of certain forensic experts' reports is also indicated by the fact that during a survey on judges and investigators it was established that in their practice they had encountered false forensic expert information $-6.6 \%$ (judges) and 5.3\% (investigators). Thus, the information that is provided by a forensic expert in the form of an expert opinion, clarification, or consultation may have signs of falsity and be the subject of further investigation in criminal proceedings. In this situation, various investigative actions can already be carried out as well as expert studies on this document (expert opinion), with a view to establishing the authorship of the text, performing signatures, details, the order of their application, the fictitiousness of the studies themselves, etc.

A survey on forensic experts made it possible to reveal that they experienced unlawful influence in order to obtain a false opinion $(24.3 \%)$. Moreover, this impact came from the suspect or accused's lawyer $(7,75 \%)$, the suspect (accused) or their relatives $(6,95 \%)$, from anonymous persons $(5,1 \%)$, as well as from the heads of the expert institution $(1,9 \%)$. An example of such unlawful influence imposed on a forensic expert is a case that occurred in Kharkiv in 2007. Persons B. and D., wishing to evade criminal liability, forced the forensic expert (with the help of physical threats to him and his relatives) to form a deliberately false expert opinion. Thus, the criminal proceedings initiated in the case of a knowingly false expert report under art. 384 of the Criminal Code of Ukraine led to a criminal prosecution for an infringement on the life and health of the forensic expert and his relatives. 
The means of counteracting such a negative impact on the forensic expert is minimizing the possibility of personal contact of the forensic expert with the expert service customer, conducting repeated expert investigations, selecting a forensic expert from the appropriate roster of judges, creating a market for forensic sciences services and their competition, as well as conducting internal and external review of the research conducted based on ENFSI instructions and guidance. In addition, the certification of experts and the accreditation of expert institutions are important, since monitoring the appropriateness of the applied methods and the forensic expert's knowledge in practice is an important component in providing a true and correct forensic expert's report to the prosecution, the defense, as well as the court.

\section{References}

Criminalistics: Textbook, vol. 1, ed. V.Yu. Shepitko, Kharkiv 2019.

Great Ukrainian juridical encyclopedia, vol. 20. Criminalistics, forensic sciences, juridical psychology, ed. V.Yu. Shepitko, Kharkiv 2018.

Honhalo S.Y., Haiduk O.H., Volchuk L.S., "Unidentifying studies of handwriting: current situation and development prospects", Journal of National University "Ostroh Academy". "Law" Series, 11, 2015. no. 1.

Kaiko V.I., Matsyievska S.M., "To the question of expert characterization of individual psychological features of the personality from the handwriting", Bulletin of Alfred Nobel University. Series "Pedagogy and Psychology". Pedagogical Sciences 16, 2018 no. 2.

Kobylianskyi O., Trofimchuk G., "Criminalistic analysis of special means of document protection against forgery", Entrepreneurship, economy and law, 2017, no. 3.

Kochura O.O., "Definition of the concept of 'specialized knowledge' and its use in criminal proceedings", [in:] Current trends in the development of criminalistics and criminal trial, Kharkiv, 2017.

Kohutych I.I., "Graphological analysis in criminalistics and its prospects", [in:] Interdepartmental scientific-practical collection "Criminalistics and Forensics", ed. O.H. Ruvin et al., Kyiv 2017.

Kohutych I.I., "Selected issues of the essence and forms of using specialized knowledge in criminal proceedings", Bulletin of the Academy of Advocacy of Ukraine 12, 2015, no. 2 .

Korabliov A.A., "Forms of using specialized knowledge in criminal proceedings", Society: Politics, Economics, Law, 2016, no. 2.

Kosmina N.M., "Specialized knowledge of informed persons during the investigation of drug trafficking and its structure", Forensic Bulletin 19, 2013, no. 1. 
Maliutin M.A., "Specialized knowledge as examination evidence", OSU Bulletin 139, 2012, no. 3.

Saltevskyi M.V., Criminalistics, vol. 1, Kharkiv 1999.

Shepitko I.I., Judicial examination in the system of judicial proceedings at first instance: A monograph, Kharkiv 2018.

Shepitko V.Yu., Criminalistics: A course of lectures, Kharkiv 2005.

Tetiuhin I.N., Enhovatova K.H., "Scientific basis criminalistic handwriting research", Questions of Modern Science and Practice 56, 2015, no. 2.

Tikhonova V.I., Zakharova T.O., "Research of extremely advanced documents", [in:] Theory and practice of judicial examinations and criminalistics, Kharkiv 2010.

Vorobey O.V., "Forensic-technical examination of documents: Basic concepts, origin and prospects of development", Judicial Practice 2010, no. 11-12. 